\title{
Cytostatic Therapy in Metastatic Breast Cancer
}

\author{
Elmar Stickeler ${ }^{\mathrm{a}^{*}} \quad$ Volker Möbus ${ }^{\mathrm{b}^{*}}$ \\ aUniversitätsfrauenklinik Freiburg i.Br., \\ bFrauenklinik, Städtische Kliniken Frankfurt Höchst, Germany
}

\author{
Key Words \\ Breast cancer, metastatic - Cytotoxic therapy . \\ Treatment effects
}

\section{Summary}

Metastasized breast cancer is still incurable. However, improvements in both efficacy and tolerability of systemic cytotoxic therapy led to prolongation of treatment with consecutive improvement of survival. While previous response to chemotherapy is an established predictive factor for expected efficacy of cytotoxic agents in the metastatic setting, the early use of 'new' effective drugs, like taxanes, may compromise the physician's choice of substances. The evaluation of patient compliance before therapy is essential as well as an assessment of the potential representative parameters (lead metastases, tumor markers, symptoms) which help to objectify the treatment effects. In general, due to the incurable situation of metastatic breast cancer, treatment effects and their benefits have to be weighed against toxicity since good quality of life is the major goal in management of this stage of disease.

\footnotetext{
*As members of the Breast Commission, part of the AGO (Working Group Gynecologic Oncology, German Society of Obstetrics and Gynecology)
}

\author{
Schlüsselwörter \\ Mammakarzinom, fortgeschrittenes . \\ Zytostatische Therapie · Behandlungseffekte
}

\section{Zusammenfassung}

Das metastasierte Mammakarzinom ist nicht heilbar, dennoch konnten durch Verbesserung der Effektivität und Verträglichkeit von systemischer Chemotherapie die Krankheitsverläufe gemildert und die Überlebenszeit deutlich verlängert werden. Das Ansprechen auf eine vorherige Chemotherapie ist einer der wichtigsten Prädiktoren für die zu erwartende Wirksamkeit eines weiteren Chemotherapieregims. Allerdings ist durch den heute zu beobachtenden frühen Einsatz hochaktiver Substanzen, wie Taxane und Anthrazykline, der Einsatz von Therapeutika für den behandelnden Arzt eingeschränkt, insbesondere, wenn nur ein kurzes therapiefreies Intervall nach Beendigung der adjuvanten Chemotherapie vorliegt. Vor Therapiebeginn ist die Einschätzung der Compliance einer Patientin ebenso essentiell wie die Definition von Parametern (z.B. Zielmetastasen, Tumormarker, Symptome), die helfen, die Therapieeffekte zu objektivieren. Generell gilt speziell für die palliative Situation, dass die Therapieeffekte und deren Benefit gegen die therapieinduzierten Toxizitäten und Nebenwirkungen abgewogen werden müssen, da ein langfristiger Erhalt der körperlichen Aktivität bei guter Lebensqualität das Hauptziel in der Behandlung ist.

\begin{tabular}{ll}
\hline KARGER & ๑ 2006 S. Karger GmbH, Freiburg \\
Fax +497614520714 & Accessible online at: \\
$\begin{array}{l}\text { E-mail Information@Karger.de } \\
\text { www.karger.com }\end{array}$ & www.karger.com/brc \\
&
\end{tabular}


Metastasized breast cancer is still incurable. However, due to improvements in efficacy and tolerability of cytotoxic treatment this stage of disease has transferred into a more chronic course with major implications for treatment options and management.

Before starting treatment it is important to evaluate the compliance, especially in older patients with reduced general condition and comorbidities. During therapy it is important to assess toxicities (subjectively and objectively) to determine the therapeutic index. Discontinuation of therapy is advised if the index turns negative. Furthermore, all doses should be administered according to published therapy protocols. For evaluation of treatment efficacy the definition of representative indicator parameters (e.g. lead metastases, tumor markers or symptoms) before therapy and about bimonthly under therapy is necessary. In case of disease progression or intolerable toxicity, treatment should be discontinued immediately. The value of cytotoxic maintenance therapy until disease progression is questionable and should generally be avoided. In individual patients who receive monotherapy, maintenance therapy might be considered even if no survival benefit was shown for this concept, so far.

The decision whether mono- or polychemotherapy should be administered has to be based on the patients expectations, age, performance status, metastatic pattern, progression of disease and previous regimens. Cytotoxic monotherapy is characterized by a favorable therapeutic index with good efficacy, moderate side effects and is indicated in cases of slow, not life-threatening progression, primary resistance or secondary progression under endocrine therapy. Polychemotherapy shows in addition to the recently demonstrated improvement of survival higher response rates accompanied by higher toxicity and impairment of quality of life $[1,2]$. This concept is preferred in patients who are in need for fast response in case of extensive visceral metastasis or symptomatic disease.

Overall, a survival benefit has been shown in recently published single randomized trials (LOE 1). All of these studies investigated taxanes in combination with a second substance including capecitabine, gemcitabine or doxorubicin [1, 2]. Interestingly, the percentage of crossover from standard to investigational therapy plays a major role and must be considered in the interpretation of these studies. However, in 4 trials a significant survival benefit has been shown (fig. 1).

The most active substances, which are recommended for first-line monotherapy in metastatic breast cancer, are anthracyclines (also their liposomal preparations), taxanes and vinorelbine (fig. 2). The advantage of liposomal doxorubicin is seen in its toxicity profile which is less cardiotoxic and allows its application beyond the cumulative anthracycline threshold or in case of cardiac disease. The polychemotherapy regimens of choice contain the combination of taxanes with anthracyclines, capecitabine or with gemcitabine. Alternatively, 5-flurouracil/(epi-) doxorubicin/

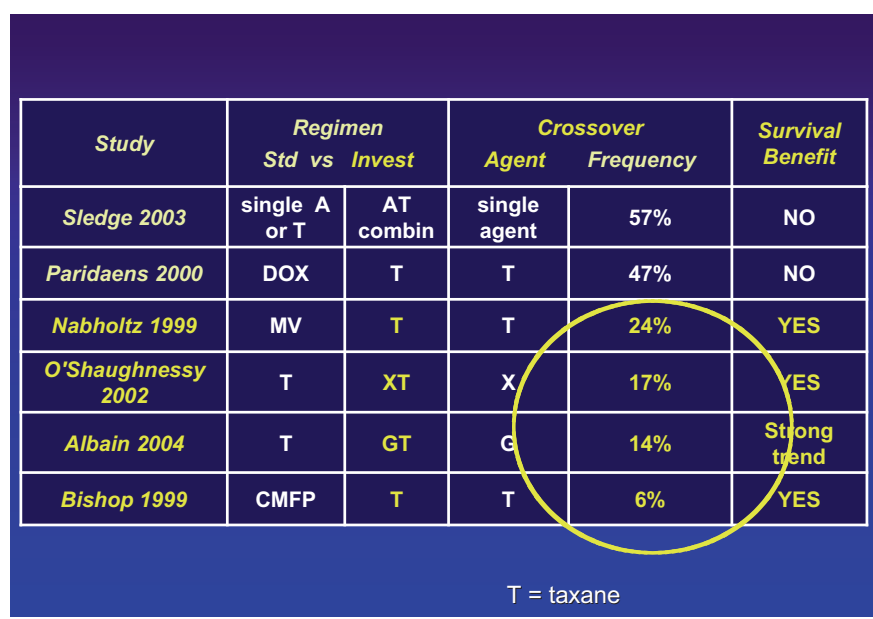

Fig. 1. Impact of cross-over design in breast cancer study designs.

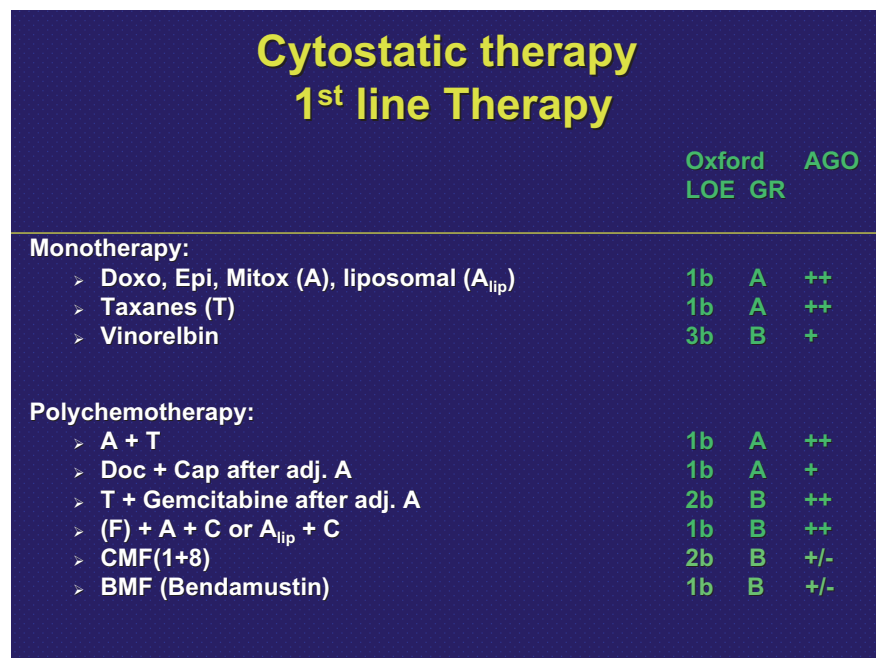

Fig. 2. First-line cytostatic therapy in metastatic breast cancer.

cyclophosphamide or liposomal doxorubicin/cyclophosphamide and CMF might be applied, even if with a lower grade of recommendation.

In the critical situation of metastatic disease after anthracyline treatment, both taxanes (docetaxel, paclitaxel) and capecitabine are substances of first choice, but liposomal doxorubicin and vinorelbine may also be used (fig. 3). Docetaxel as monotherapy was found to be the only regimen which improved survival in metastatic breast cancer after anthracyline treatment. The Cochrane metaanalysis 2003 revealed a significant survival advantage for the taxanes in metastatic disease against non-taxane regimens. No significant differences were found with regard to quality of life and treatment related deaths. The final assessment was compromised by the heterogeneity of the underlying studies. Indirect comparison of docetaxel and paclitaxel revealed a trend towards higher efficacy for docetaxel $[3,4]$. However, due to the distinct toxicity profiles of both substances the use for each taxane has to be considered individually for each case. 


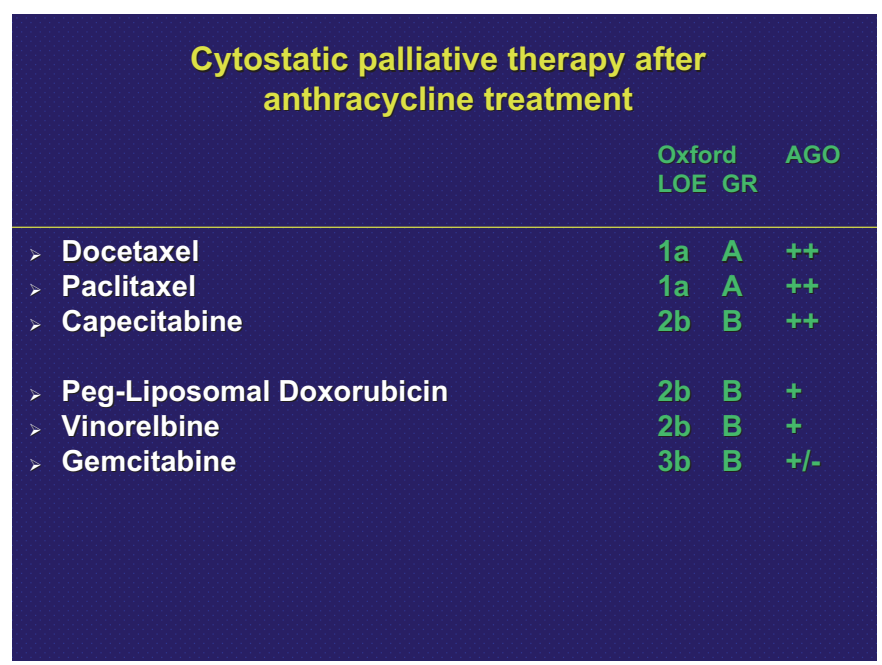

Fig. 3. Palliative cytostatic therapy in metastatic breast cancer after anthracyline treatment.

Cytostatic therapy after anthracycline and taxane failure is associated with very low response rates. The literature survey reveals efficacy for capecitabine, liposomal doxorubicin and vinorelbine with response rates up to $35 \%$ and a median sur-

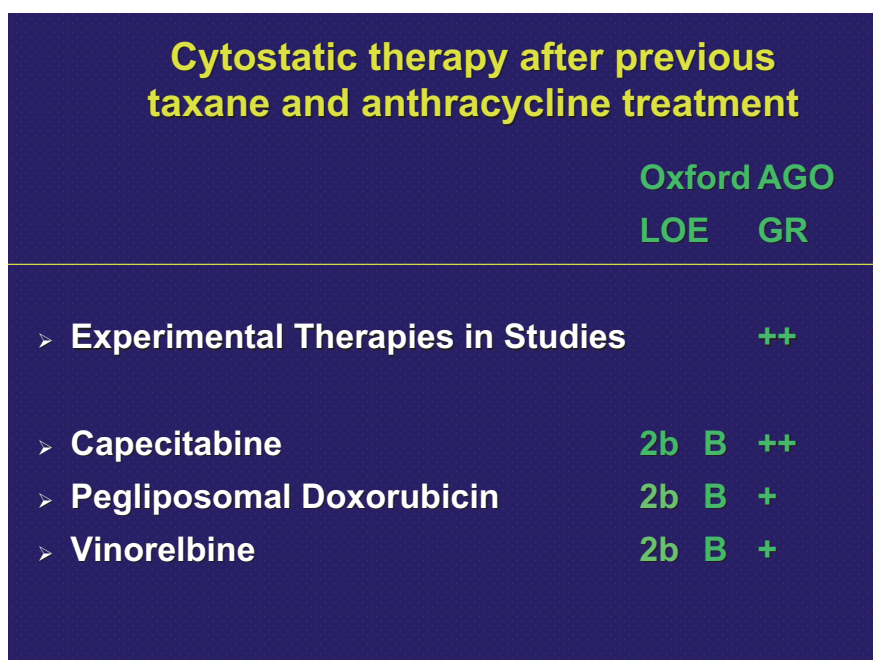

Fig. 4. Cytostatic therapy in metastatic breast cancer after first-line taxane and anthracyclin treatment.

vival of 9-13 months [5, 6]. If possible, treatment should be preferably performed in clinical trials. Palliative high-dose chemotherapy is not recommended (fig. 4).

\section{References}

1 O'Shaugnessy J, Miles D, Vukelja S et al.: Superior survival with plus docetaxel combination therapy in anthracycline-pretreated patients with advanced breast cancer: phase III trial results. J Clin Oncol 2002;20:2812-2823.

2 Albain KS, Nag S, Calderillo-Ruiz G et al.: Global phase III study of gemcitabine plus paclitaxel (GT) vs. paclitaxel (T) as frontline therapy for metastatic breast cancer (MBC): First report of overall survival. ASCO Annual Meeting Proceedings 22. J Clin Oncol 2004;14S:510.
3 Gershi D, Wilcken N, Simes J, Donoghue E Taxane containing regimens for metastatic breast cancer. Cochrane Database Syst Rev 2003;3: CD003366.

4 Jones S, Erban J, Overmoyer B, Ravdin PM: Randomized trial comparing docetaxel and paclitaxel in patients with metastatic breast cancer.San Antonio Breast Cancer symposium 2003:abstr 10.

5 Fumuleau P, Largillier R, Clippe C et al.: Multicenter phase II study eveluating capecitabine monotherapy in patients with anthracycline- and taxanepretreated metastatic breast cancer. Eur J cancer 2004;40:536-540.
6 Keller AM, Mennel RG, Georgoulias D et al. Randomized phase III trial of pegylated liposomal doxorubicin versus vinorelbine or mitomycin $\mathrm{C}$ plus vinblastine in women with taxane-refractory advanced breast cancer. J Clin Oncol 2004;22 3893-3901. 